\title{
"SEA INSPIRATION" COLLECTION INNOVATIVE DRESS- FORM DESIGNS INSPIRED BY THE MARINE ENVIRONMENT USING SHELLS
}

\author{
Najwa Shukry Muhammad MOAMEN, Doaa Muhammad ABBOUD *
}

Department of Apparel and Textile, Faculty of Home Economics, Helwan University, Egypt

\begin{abstract}
The design on the mannequin or the artistic composition on the mannequin is one of the languages of art that addresses the senses and makes.Man is predisposed to contemplation and imagination, and the source of the design formed on the mannequin may be borrowed from history, nature, or events in which we live, so the design artist on the mannequin is affected by the surrounding environment, and may reformulate it through designs that express see and feel. Also designing on the mannequin is a plastic art that requires a delicate sense of beauty and the ability to imagine, and allows the designer. The launch of the expression of his creative innovations and creative touches spontaneously and complete freedom of expression away from restrictions and thought traditional.

Keywords

Sea Inspiration, Collection, Innovative, Dress-form Designs, Marine Environment, Shells.
\end{abstract}

\section{Introduction}

In order for the designer's ideas to become reality and details into reality, he crystallizes and translates the ideas into the mannequin through the most important. The tools of creativity in mannequin design style are materials and fabrics with all their color and weight properties. The texture, the degree of draining or hardness, transparency or thickness, and other characteristics, fabrics represent a source of inspiration that translates ideas. And the designer's sense to produce artistic creations of mannequins that bear originality and aesthetic dimension and reflect the designer's vision.

Some studies in the field of fashion design have been concerned with the natural environment and taking advantage of its aesthetics, such as studying both: Wafaa Adel Abu Arayes - 9072 and Nancy Abdel Maaboud - who inspired evening wear for women from flowers. The first study used the design and formation on the mannequin, and the second study used the Photoshop program, Also the study of Ashraf Abdel Hakim - which aimed to provide new design visions through an in-depth study of systems geometric in natural elements such as the radiative geometric system represented by the lines that appear on the surface of seashells, These elements were reworked, and some designs were executed in the mannequin style.

Shells are distinguished by their creative colors, varied shapes, and different sizes that make them used in the world of art something enjoyable, as the Creator, may He be glorified and exalted, granted it a special magic, and a diversity that allows the freedom to choose what suits

* Corresponding author: homeecon@helwan.edu.eg 
the artwork that we do by creating it according to its type and function.

The concept of art supports the relationship between the environment and the human being, and this is what the art of design can offer on the mannequin, given one of the methods of fashion design is using cloth directly, in sending an artistic, aesthetic message bearing an intellectual character to renew and revive our relationship nature, through artistic works of coexistence with a part of our environment, which is the sea environment that was and still is a fertile source for many artists to draw inspiration from distinguished works of art, and Mervat El-Sherbiny achieved this concept through her inspired studies innovative design formulas from sea snails to enrich the decorative painting, as is the study of Nahla Hamed - which was concluded by:

Innovated textural formulations based on snails and shells as experimental approaches for specific education students.

In the field of fashion, Ola Yousef et al .'s study included shells as a source for designing clothes. The evening was done using the mannequin modeling method, and the opinions of a sample of specialists and other consumers were measured Reviews are positive for most of the designs for the two samples. Amal Abdel Samie addressed the coral reefs of the sea in her study red to enrich the decorative design of women's evening wear using Photoshop.

From the perspective that design on a mannequin is a plastic art that contains the basic expressive art values and relations, including It includes balance, rhythm and harmony in which the artist's imagination plays a fundamental role through his interaction with the environment in which he lives. Its natural aesthetic aspects, so the current research has adopted one of the innovations of the environment; They are the beach, sea, shells and pearls environment an attempt to renew and revive the relationship with nature, using a method that helps innovate and liberate thought from constraints, which is determination Mannequin; to create innovative expressive artistic designs that invite contemplation of the aesthetics of nature around us, inspired by the sea environment in a group of designs that mainly include shells, which are a component of the marine environment, called those the group "Inspired by the Sea".

\section{Research problem}

The research problem is how to highlight the aesthetics of the natural environment of the seashore, through the creation of a group designed, On the mannequin the group has been called "inspired by the sea" with the use of one of the basic components of that environment, namely the existing shells. On the beach or at sea. Depending on what was presented in the introduction and the research problem, the following research questions can be formulated:

1- What is the possibility of creating a "inspired by the sea" collection inspired by the aesthetics 
of the natural sea environment using shells?

2-What are the opinions of specialists in the fields of mannequin formation - fashion design textile design and printing - plastic artists for the "inspired by the sea" group?

\section{Research importance}

- The set of designs presented in the research may benefit specialists in other fields such as expressive fashion or complementary Clothing.

- The research contributes to directing the artists' thought towards using shells as one of the raw materials of the natural environment in other artistic treatments.

- Openness to dealing with diverse natural environments in research, to revive the relationship with nature and benefit from the aesthetics that abound out.

\section{Research aims}

The research aims to achieve the following:

- Designing a group "Inspired by the Sea" inspired by the aesthetics of the natural sea environment, with shells being an essential component in all group designs.

\section{Research Methodology}

The research followed the descriptive approach for its relevance to achieving goals and reaching results.

\section{The research sample}

The previous table shows the description of the research sample of specialists, whose total number was 17. The two researchers, provided that the sample members include specialists in various fields and technical aspects related to aspects of the research subject. And a group of "Revelations of the Sea" in particular, in order to enrich the results of the research and identify different opinions and responses to each, Therefore, the sample consisted of 79 specialists in the field of shaping on the mannequin, as well as specialists in the field of fashion design, number 1 , and in the field of textile design and printing, number 1, in addition to plastic artists and their number is 92 .

\section{Recommendations:}

- The necessity of linking art and the environment with an aesthetic concept that enriches and develops the creative experience of fashion and art scholars.

- The importance of identifying and studying the environment as an important and main source of innovation and creativity.

- Conducting workshops to develop innovation and raise the level of appreciation to create new plastic formulas for specialized students and those interested in fashion and art, the environment is the focus of work and take inspiration from its aesthetics. 
-Activating the results of conferences held in the field of environment and arts, and adopting recommendations by the concerned authorities.

- Nurturing, encouraging and adopting talented and innovators in the fields of art and fashion in different stages of life, and directing them to benefit

from the natural environment sources.

- The necessity for students to experiment with and be inspired by non-traditional environmental sources, as a formative medium to express the art of design fashion.

\section{References}

- The Brief Lexicon 7222: The Academy of the Arabic Language - c. M. P.

- The Arab Scientific Illustrated Encyclopedia 7221: Part VIII Al-Ahram Foundation

- Ahmed Raafat Abdel-Gawad 7212: Principles of Aesthetics, Cairo, Nahdet Misr Bookshop.

- Amal Abdel Samie: Benefiting from some of the coral reefs of the Red Sea to enrich the decorative design of the dresses

- Al-Sahra - Specific Education Research Journal - October issue.

- Ashraf Abdel Hakim: An artistic vision of women's fashion design in light of the geometric systems of natural elements - Science Magazine And Arts - April issue.

- Iman Ahmed Mohamed 9079: Plastic formulations using shell materials inspired by the symbols of popular art as an introduction to enriching Artifacts - Unpublished Master Thesis Faculty of Specific Education - Department of Education - Art, Menoufia University.

- Gilan Abdel Wahab Mohamed 9009: Innovative plastic formulations using shell materials as an input to ornamental supplements - a message Unpublished MA - Faculty of Art Education Helwan University.

- Doaa Ahmed Ezz 9072: Snails and Shells in Folk Art and Using them to Create Contemporary Artistic Works - Unpublished Master Thesis - College of Education - Minia University.

- Salama Muhammad Ali, Muhammad Ibrahim Al-Shorbaji, Aya Ahmed Al-Hanafi: Artistic Visions of Selected Marine Organisms And to benefit from it in building sculptural formation - the twelfth annual Arab scientific conference - the ninth international to develop outputs Quality education in Egypt and the Arab world in light of global competitiveness - Faculty of Specific Education - Mansoura University - April issue.

- Mercury Khalil, Shaima Farid 9072: The Reality of Environment and Energy Statistics in Iraq - Central Statistical Organization - Ministry

Planning - Republic of Iraq.

- Ola Yusef, Suha Muhammad Hamdi, Shaima Mustafa: Shells as a source for style evening wear designs Mannequin Formation - The Fifth International Scientific Conference on 
Education and Entrepreneurship "Challenges and Development" - College of Education Quality - Menoufia University.

- Lamia Hassan Al-Sanhouri 9002: Creating new technical treatments for environmental materials to create fashion in the style of shaping The Mannequin - Unpublished Master Thesis - Faculty of Home Economics - Helwan University.

- Muhammad Ahmad Bani Salama 9001: Environmental Sculpture through the works of the artist Goldsworthy, Analytical Study - Master Thesis - Faculty of Fine Arts - Yarmouk University - Jordan.

- Mervat El-Sherbiny 9079: Innovative design formulas inspired by sea snails to enrich the aesthetic values of the decorative painting - Unpublished $\mathrm{PhD}$ thesis - Faculty of Specific Education - Mansoura University.

Nancy Abdel-Maaboud El-Sawy: Creating Evening Wear Designs Inspired by Natural Flowers - Magazine Alexandria Science - Volume 22 - Issue 2.

- Nagwa Shoukry, Suha Abdel Ghaffar 9002: Formation on the Mannequin - House of Arab Thought - Cairo.

- Najwa Shukry, Mona Sidqi, Hanan Nabih, Iman Abdel Salam 9070: Formation on Manichaan between Originality and Modernity - Edition 9 - The World of Books.

- Nagwa Shoukry, Hanan Nabih, Amr Hassouna 9079: Basics of Mannequin Formation - House of Arab Thought.

- Najwa Shukry, Hanan Nabih, Doaa Abboud 9070: Modern Techniques in Preparing Mannequins for Formation - Edition 9 The World of Books.

- Nahla Ali Hamed: innovative textural formulations based on snails and shells as experimental approaches for education students Qualitative - an "unpublished" master's thesis - Faculty of Specific Education - South Valley University.

- Wafa Adel Abu Arayes 9072: Technical Treatments for Elements of Flowers in Nature as a Rich Source of Inspiration for Designing and Forming Fabrics on Mannequins - Unpublished Master Thesis - Faculty of Home Economics - University of Menoufia.

- Marwa Youssef ALSAYAD, MUSIC IN SHADE OF TECHNOLOGICAL DEVELOPMENT BETWEEN HARM AND BENEFIT, International Journal of Humanities and Language Research, Vol. 1, No. 2, 2018, pp. 13-21. 